\title{
O debate no Novo Mundo: representações do homem americano nos séculos XVII e XVIII
}

\author{
Luis Guilherme Assis Kalil ${ }^{1}$
}

SILVA, Bruno. As cores do Novo Mundo: degeneração, ideias de raça e racismos nos séculos XVII e XVIII. Lisboa: Lisbon, 2020. 460p.

Resenha recebida em: 06/02/2021

Resenha aprovada para publicação em: 07/04/2021

Quando Diderot e d'Alembert concluíram a Encyclopédie, esse enorme empreendimento intelectual coletivo que buscava concentrar e ordenar o conhecimento possuía mais de 70.000 artigos. No entanto, nenhum deles era dedicado à América. A falta de um verbete sobre o continente americano no que foi descrito por Robert Darnton (1986, p. 247) como “o texto supremo do Iluminismo" é reveladora do espaço dedicado ao Novo Mundo nas reflexões de alguns membros da intelectualidade europeia do período das Luzes. A partir de lógicas hierarquizadoras, as terras americanas e seus habitantes foram, muitas vezes, relegados aos estágios inferiores de desenvolvimento ou de "civilização".

Essa ausência viria a ser contornada apenas no Supplément à l'Encyclopédie, publicado entre 1776 e 1777, que não contou com a participação direta dos principais organizadores da obra original. Nele, o verbete Amérique ${ }^{2}$ é dividido entre dois autores. As questões geográficas entremeadas por debates acerca da fiabilidade das fontes sobre o Novo Mundo foram abordadas por Samuel Engel, cartógrafo ilustrado suíço que já havia dedicado uma obra ao continente americano, na qual buscava determinar como, quando e por quem essas terras teriam sido povoadas (ENGEL, 1767). Por sua vez, as discussões envolvendo os indígenas, a natureza e as influências deletérias do clima

\footnotetext{
${ }^{1}$ Doutor em História Cultural pela Universidade Estadual de Campinas (UNICAMP). Professor adjunto de História da América Colonial e América Independente no século XIX e membro do Programa de Pósgraduação em História (PPHR) da Universidade Federal Rural do Rio de Janeiro (UFRRJ - IM/Nova Iguaçu). Av. Governador Roberto Silveira s/nº, Moquetá, Nova Iguaçu, RJ, CEP: 26285-060. E-mail: lgkalil@yahoo.com.br.

2 Disponível em: artflx.uchicago.edu/cgi-bin/philologic/getobject.pl?c.1:886.supplement2.3048105. Acesso em 05 fev. 2021.
} 
couberam a Cornelius de Pauw. Em sua parte do verbete, o intelectual prussiano descreve um continente, bem como seus habitantes, marcado pela inferioridade e pela falta em seus múltiplos aspectos: de animais de carga, de disposição e maturidade para o trabalho físico e intelectual por parte de seus moradores, de condições climáticas favoráveis à agricultura e ao desenvolvimento das sociedades, entre várias outras ausências.

Assim como no caso de Engel, as reflexões de Cornelius de Pauw no Supplément derivam de trabalhos anteriores sobre a América e os americanos, particularmente os dois volumes de seu Recherches philosophiques sur les Américains (1768-1769). As teses defendidas por De Pauw, bem como suas influências intelectuais e a grande repercussão obtida por seus escritos, foram analisadas por Antonello Gerbi em sua incontornável obra

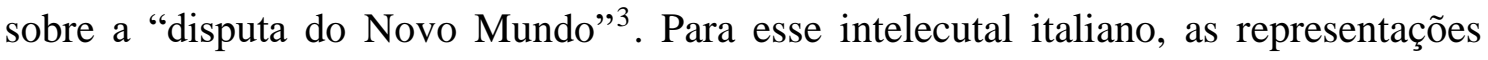
extremamente negativas sobre a América teriam Georges-Louis Leclerc, o conde de Buffon, como seu principal mentor e De Pauw como aquele que teria elevado o tom de difamação a um “insuperável extremo" (GERBI, 1996, p. 56).

Publicado originalmente na década de 1950, o livro de Gerbi continua sendo lido e debatido ainda hoje. Como exemplo, podemos citar Jorge Cañizares-Esguerra, que em seu Como escrever a história do Novo Mundo (2011) argumenta que o historiador italiano ainda reproduz muitas das visões eurocêntricas sobre esse debate intelectual. Em sua obra, o professor da Universidade do Texas enfatiza a necessidade de voltarmos nossas atenções ao século XVII para colocarmos em perspectiva as questões debatidas no período das Luzes. O autor também ressalta a importância das reflexões produzidas por intelectuais americanos, que teriam contribuído para o surgimento de uma "epistemologia patriótica" cuja importância seria fundamental para a compreensão das representações produzidas nesse período sobre o Novo Mundo, sua natureza e a de seus habitantes.

O livro de Bruno Silva, publicado no final de 2020, pode ser lido como uma importante contribuição a esse tema ainda pouco explorado em língua portuguesa ${ }^{4}$. Em seu As cores do Novo Mundo, o professor de História da América da UNIFESSPA

\footnotetext{
${ }^{3}$ Debate intelectual travado no século XVIII por escritores de ambas as margens do Atlântico a respeito da natureza da América e dos americanos. Para uma introdução ao tema, Cf. DOMINGUES, 2017.

${ }^{4}$ Entre os poucos exemplos de pesquisadores brasileiros que dialogam com a obra de Antonello Gerbi, podemos citar Flávia P. de Godoy Oliveira (2010) e Beatriz Helena Domingues (2007), que destaca a participação de jesuítas de origem portuguesa nessa "disputa", algo pouco trabalhado pelo pesquisador italiano.
} 
recupera os argumentos de autores como Gerbi e Cañizares-Esguerra como ponto de partida para refletir sobre a historicidade das ideias envolvendo raça e racismo e produzir um "inventário do homem americano" (2020, p. 23). Para ele, as principais questões sobre a natureza da América e de seus habitantes já se encontravam amplamente difundidas muito antes dos escritos de Buffon e De Pauw, comumente apontados como pioneiros dentro desses debates. Com esse intuito, o autor, como o próprio subtítulo da obra indica, centra sua atenção na associação entre as ideias envolvendo degeneração, raça e racismo.

De acordo com o pesquisador, as representações produzidas nos séculos XVII e XVIII enfatizando a condição degenerada do homem americano seriam fundamentais para o surgimento de um novo significado associado à noção de raça, não mais relacionada a questões religiosas, como era comum na Europa até então, mas a características físicas. Essa abordagem estaria presente até mesmo em obras que não utilizavam a palavra raça, uma vez que "aquilo que estava subjacente à forma como os indivíduos do Novo Mundo eram classificados pode ser considerado como racismo" (2020, p. 198).

Nesse sentido, a obra de Bruno Silva, resultado de sua tese de doutorado defendida na Universidade Federal Fluminense, retoma as proposições de Jorge Cañizares-Esguerra com o intuito de questionar a centralidade atribuída à Europa das Luzes para se pensar questões como as diferenças (naturais?) entre os grupos humanos. Para isso, o autor abre mão dos recortes nacionais ou imperiais, ainda hoje muito presentes nas pesquisas sobre o período colonial, para estender suas reflexões pelas duas margens do Atlântico em suas múltiplas direções: não apenas analisando o que era produzido na Europa sobre os americanos e africanos, mas dando destaque também para o que era feito no Novo Mundo.

A obra é dividida em cinco capítulos organizados em duas partes. Na primeira delas, "Viagens, teorias e a invenção do homem americano", a ênfase recai nos viajantes que percorreram a América no período, em detrimento dos escritos produzidos por teóricos dentro de seus gabinetes em solo europeu. $\mathrm{O}$ destaque aos relatos de viagem faz com que o autor estabeleça critérios para dividir sua análise entre os viajantes religiosos, cientistas, militares e aqueles que empreenderam expedições particulares. A partir dessa divisão, Silva destaca as redes de sociabilidades, favores e contatos familiares, que autorizavam viagens, garantiam cargos e mercês, permitiam a publicação e circulação de 
obras e favoreciam - ou não - a repercussão de seus argumentos. Com esses critérios, o autor apresenta um extenso levantamento de fontes sobre o tema, destacando algumas delas como importantes para se perceber as mudanças epistemológicas que vinham ocorrendo no período. Como exemplo, podemos mencionar sua análise sobre os escritos de François Bernier, intelectual francês do final do século XVII identificado como o responsável pela "primeira tentativa de dividir a humanidade em raças, considerando, sobretudo, a cor da pele dos indivíduos" (SILVA, 2020, p. 77).

A identificação das fontes seiscentistas como ponto de partida para se pensar as temáticas abordadas no livro levam o autor a afirmar que "os viajantes e filósofos do século XVII degeneraram o homem americano; os letrados da centúria seguinte se encarregaram de teorizar sobre a degeneração" (SILVA, 2020, p. 111). Ainda que não fosse possível expandir ainda mais o recorte temporal selecionado, devido às limitações inerentes a uma pesquisa de doutorado, seria interessante reforçar o que o autor identifica como especificidades dos debates sobre a América no século XVII, tendo em vista as características que os diferenciariam das reflexões produzidas desde a chegada de Colombo - ou mesmo antes - sobre temas como a natureza do Novo Mundo, a(s) origem(ns) dos americanos ou a habitabilidade das zonas tórridas. Ao longo da obra, o autor demonstra, com riqueza de detalhes, que discussões comumente associadas ao período das Luzes já estavam em pauta no século anterior. No entanto, seria interessante destacar de que formas elas se diferenciariam das reflexões produzidas no início da presença europeia na América, o que reforçaria a tese de que algo original a respeito das representações dos indígenas e da natureza americana teria surgido no século XVII.

A segunda parte do livro, "A degeneração e a composição das raças nos séculos XVII e XVIII", apresenta um extenso e erudito mapeamento em torno do conceito de raça. Retomando sua tese de que a ideia de raça, considerando os aspectos físicos, teria nascido no Novo Mundo associada ao processo de degeneração do homem americano, o autor dialoga com a produção bibliográfica produzida nas últimas décadas e analisa detidamente verbetes de enciclopédia, dicionários e outras fontes do período em busca dos diferentes significados atribuídos a palavras como raça, nação ou tribo. Ecoando os alertas de Marc Bloch e Lucien Febvre, Silva demonstra que as ideias podem mudar 
enquanto as palavras permanecem as mesmas e, simultaneamente, "o conteúdo pode existir antes do nome que o expressa" (2020, 436-438).

Como resultado, As cores do Novo Mundo contribui para aprofundar as reflexões sobre raça e racismo. $\mathrm{O}$ esforço em historicizar esse processo se associa à utilização de recortes temporais e geográficos que deslocam o centro do debate da Europa das Luzes para outras épocas e regiões, questionando escolhas e decisões reproduzidas por gerações de historiadores e, ao mesmo tempo, ressaltando silêncios duradouros.

\section{Referências bibliográficas}

CAÑIZARES-ESGUERRA, Jorge. Como escrever a história do Novo Mundo: Histórias, Epistemologias e Identidades no Mundo Atlântico do Século XVIII. São Paulo: Edusp, 2011.

DARNTON, Robert. O grande massacre de gatos; e outros episódios da história cultural francesa. Rio de Janeiro: Graal, 1986.

DOMINGUES, Beatriz Helena. Tão Longe, tão perto: a Ibero-América e a Europa Ilustrada. Rio de Janeiro: Editora Museu da República, 2007.

DOMINGUES, Beatriz Helena; SANTOS; Breno Machado dos. Entre textos, contextos e epistemologias: apontamentos sobre a "Polêmica do Novo Mundo". In: CAÑIZARESESGUERRA, Jorge; FERNANDES, Luiz Estevam de Oliveira; BOHN MARTINS, Maria Cristina (orgs.). As Américas na Primeira Modernidade. Curitiba: Editora Prismas, 2017, p. 317-359.

ENGEL, Samuel. Essai sur cette question: quand et comment l'Amérique a-t-elle été peuplée d'hommes et d'animaux?. Amsterdam: Marc Michel Rey, 1767.

GERBI, Antonello. O Novo Mundo; história de uma polêmica: 1750-1900. São Paulo: Companhia das Letras, 1996.

GODOY, Flávia Preto de. Entre o fabuloso e o verossímil; crônicas e epistemologia no processo de cognição da América. Campinas: Unicamp, 2010. (Dissertação, Mestrado em História Cultural). 